\title{
Sella Turcica Bridging as a Predicator of Dentofacial Anomalies: A Cephalometric Anolusis
}

\author{
Dr Shantanu Dixit,' Dr Dashrath Kafle,2 Dr Michael Bornstein,3 Dr Seshananda Sanjel4 \\ 'Lecturer, Dept of Oral Medicine \& Radiology: ${ }^{2}$ Assoc Prof, Dept of Orthodontics, \\ 4Lecturer, Dept of Community Medicine, Kathmandu University School of Medical Sciences, Dhulikhel, Nepal \\ 3Professor, Oral \& Maxillofacial Radiology, Applied Oral Sciences, Faculty of Dentistry, \\ The University of Hong Kong, Hong Kong SAR, China
}

Correspondence: Dr Shantanu Dixit; Email: drshantanudixit@gmail.com

\section{ABSTRACT}

Introduction: Sellar changes are associated with several dentofacial anomalies. Clinicians should be aware of different morphological varaiants of sella turcica (ST).

Objective: To find the prevalence of sella turcica bridging and to analyze the absence or presence of bridging with a spectrum of dentofacial anomalies.

Materials \& Method: 710 case records were selected from the database; out of which 473 subjects met the inclusion criteria. 280 lateral cephalogram revealed a normal shape of ST. Among them, 71 subjects were selected by interval sampling which were taken as the control group. Among initial 473 subjects, 78 samples showed ST bridging and were taken as the study group. Dental casts and radiographs (panoramic and cephalometric) were evaluated to find any dentofacial anomalies. Subjects were divided on the basis of dentofacial anomalies such as abnormal tooth position, size, shape, number, malocclusion, sagittal skeletal relationship. Chi-square test and binomial logistic regression analysis were done to find the association and correlation among the variables.

Result: In the study group, 32 subjects showed a complete bridging and 46 subjects a partial bridging of the sella turcica. There was no significant association between ST bridging and age, gender or ethnic groups. However, there was significant association $(p=0.001$ ) between the presence of bridging and dentofacial anomalies when compared with the control group.

Conclusion: The occurrence of ST bridging is $16.49 \%$ with no association to age, gender and ethnic groups in a Nepalese sample. Sella turcica bridging can be used as a diagnostic tool for early prediction of dentofacial anomalies.

Key-words: bridging, dentofacial anomalies, sella turcica

\section{INTRODUCTION}

Sella turcica (ST) is a saddle-shaped structure located on the intracranial surface of the sphenoid bone in the middle cranial fossa.' ST can be divided anatomically into anterior wall (tuberculum sellae), floor, and posterior wall (dorsum sellae). Axelsson et $\mathrm{a}^{2}$ classified morphological variants of ST into: oblique anterior wall, double contour of the floor, irregularity (notching) in the posterior part of the dorsum sellae, pyramidal shape of the dorsum sella and ST bridging. Kucia et $a^{3}$ added three other variants: hypertrophic posterior clinoid process, hypotrophic posterior clinoid process, and oblique contour of the floor.

ST is an important and commonly used landmark for cephalometric tracings. The relationship of pituitary gland pathology and endocrine disease is the result of their common embryological origin, which are the cranial neural crestal cells of early chondrocranium. ${ }^{1,4,5}$ Same cells are also associated with the genesis of both ST and derivatives of the frontal process/first branchial arch, along with the teeth. ${ }^{6.7}$ Thus the variation in ST shape can be used as an early predictor of abnormalities related to the craniofacial complex. ${ }^{8}$

Bridging is an extensively studied morphological variant of ST. In healthy subjects, its reported incidence ranges from 3.8-13\%. ${ }^{1,2,9}$ Numerous authors have mentioned bridging as an important radiological feature in syndromes. ${ }^{10-12} \mathrm{~A}$ study revealed incidence of bridging to be $18.6 \%$ in patients with severe craniofacial deviation; whereas, another reported an incidence of $16.7 \%$ and $7.3 \%$ in patients treated with combined surgical-orthodontic therapy and only orthodontic therapy respectively. ${ }^{13}$ A significant association of ST bridging with dental anomalies such as 
palatally displaced canines, mandibular second premolar aplasia and dental transposition has been established in

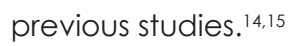

Hence, the present study aims to determine the occurrence of ST bridging in pre-orthodontic Nepalese patient samples and to compare the spectrum of different dentofacial anomalies in patients with and without bridging.

\section{MATERIALS AND METHOD}

The retrospective observational study was conducted after receiving ethical clearance from Institutional Review Committee. Case records of 710 Nepalese subjects were collected from the database of Department of Orthodontics, Dhulikhel Hospital. Cephalometric and panoramic radiographs of good quality were included. The exclusion criteria were poor visibility of ST on cephalogram, craniofacial anomaly or syndrome, and history of trauma. Dental casts and extra-oral radiographs were analyzed to detect dentofacial anomalies such as abnormal tooth position, size, shape, number, malocclusion and sagittal dental relationship (Angle Class I, II, III) following International Classification of Diseases to Dentistry \& Stomatology given by World Health Organisation. ${ }^{16}$

Among the initially screened case records, 473 subjects (66.61\%) metthe inclusion criteria. The selected radiographs were then segregated according to age, gender and ethnic groups (Newar, Brahmin, Chhetri, Mongoloid, and Madhesi). The selected cephalograms were classified into six different morphological variants of ST based on the classification by Axelsson et $a^{2}$ (Figure 1). The classification of ST on cephalograms was done independently by an oral radiologist and an orthodontist. The initial grouping of 473 lateral cephalograms resulted in 280 (59.19\%) STs with a normal shape. Out of these, 71 (25.35\%) subjects (19 males and 52 females) were selected by interval sampling and taken as the control group. Among the initial 473 sample of subjects, 115 subjects $(24.31 \%)$ showed other morphological variants of ST.

Radiographs were classified according to the sagittal skeletal relationship using Steiner's analysis. Skeletal bases were grouped according to ANB angle value: Class I skeletal base: angle $2-4^{\circ}$, Class II: $>4^{\circ}$ and Class III: $<0^{\circ}$. Wits appraisal was determined when limitations of ANB angle occurred. The extent of bridging was determined by measuring the length and diameter of ST on cephalometric radiographs. ${ }^{2}$ The measurements were done manually by one observer (oral radiologist) in dark room. The contour of pituitary fossa was traced from the tip of the dorsum sellae to the tuberculum sellae on a transparent acetate sheet using $0.5 \mathrm{~mm}$ lead pencil. Length of the sellae was

measured as the distance between tuberculum sella and tip of the dorsum sellae. Diameter of ST was measured from the tuberculum sellae to the most posterior point on the inner wall of the pituitary fossa. Length and diameter of the sella were compared to score the extent of bridging, resulting into the following groups: ${ }^{14}$

Class I: No bridging (length of sella greater than or equal to three-fourths of the diameter)

Class II: Partial bridging (length of sella lesser than threefourths of the diameter)

Class III: Complete bridging (Figure 2).

Intra-observer bias was eliminated by retracing randomly selected twenty cephalograms on two different occasions within two weeks under similar conditions. Data were analyzed using SPSS Version 21. Study and control groups were segregated according to different age, gender, ethnic groups and dentofacial anomalies. Statistical comparisons included chi-square test to find the association of dentofacial anomalies in study and control groups of different age, gender and ethnicity. The statistical significance was set at $p$-value $<0.05$. Binominal logistic regression analysis was used to correlate sagittal skeletal relationships in both groups.
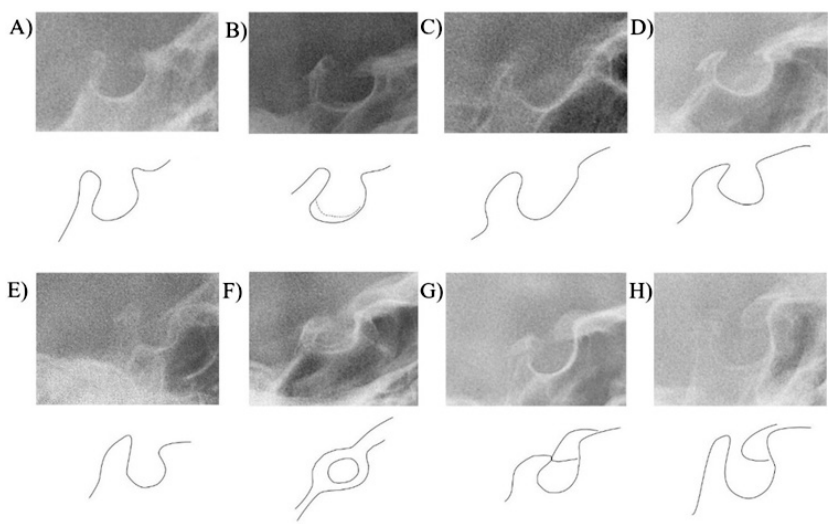

Figure 1: Morphological variants of sella turcica seen in lateral cephalogram A) normal B) double contour of the floor C) oblique anterior wall D) irregularity (notching) of dorsum sella E) pyramidal shape of dorsum sella $F, G$ ) complete bridging $\mathrm{H}$ ) partial bridging

A)
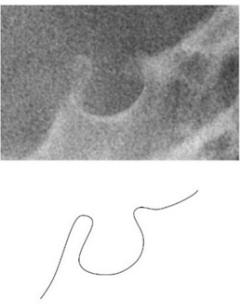

Figure 2: Variable extent of bridging A) Class I - No bridging B) Class II - Partial bridging C) Class III - Complete bridging
B)
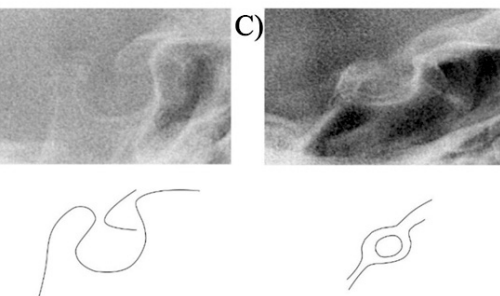


\section{RESULT}

The test group consisted of 78 (16.49\%) subjects with 30 males and 48 females exhibiting radiological bridging; among them 32 subjects $(41.02 \%)$ showed complete and 46 subjects $(58.97 \%)$ showed partial bridging. Data regarding the distribution of bridging for different age, gender and ethnic groups are shown in Table 1. The chisquare test was not significant, suggesting no association between bridging and age $(p=0.305)$, gender $(p=0.089)$, ethnicity $(p=0.559)$. In the test group, 139 anomalies were seen; whereas in the control group, 69 anomalies were seen. In both control and test groups, most common anomaly were related to tooth position, followed by malocclusion (Table 2). The study showed significant association ( $p=0.001$ ) between dental anomalies with test and control groups, suggesting that the occurrence of dental anomalies increase with bridging of sella turcica (Table 3).

Distribution of no bridging, partial bridging and complete bridging among different skeletal malocclusions is shown in Table 4. Binominal logistic regression analysis showed the presence of bridging in skeletal Class II at almost six times the rate $(\mathrm{Cl}: 2.16-17.797 ; p=0.001)$ compared to skeletal Class III (Table 5).

Table 1: Occurrence of ST bridging in different age, ethnicity, gender and their association

\begin{tabular}{|c|c|c|c|c|c|c|c|c|}
\hline \multicolumn{3}{|c|}{ Age } & \multicolumn{3}{|c|}{ Ethnicity } & \multicolumn{3}{|c|}{ Gender } \\
\hline Years & $\begin{array}{l}\text { Test Group } \\
(\mathrm{N}=78)\end{array}$ & $\begin{array}{l}\text { Control Group } \\
\qquad(\mathrm{N}=71)\end{array}$ & Type & $\begin{array}{l}\text { Test Group } \\
(\mathrm{N}=78)\end{array}$ & $\begin{array}{c}\text { Control Group } \\
(\mathrm{N}=71)\end{array}$ & Type & $\begin{array}{l}\text { Test Group } \\
(\mathrm{N}=78)\end{array}$ & $\begin{array}{c}\text { Control Group } \\
(\mathrm{N}=71)\end{array}$ \\
\hline$\leq 10$ & $1(1.3 \%)$ & $0(0 \%)$ & Newar & $35(44.9 \%)$ & $23(32.4 \%)$ & \multirow{2}{*}{ Male } & \multirow{2}{*}{$30(38.5 \%)$} & \multirow{2}{*}{$19(26.8 \%)$} \\
\hline $11-20$ & $39(50 \%)$ & $29(40.8 \%)$ & Brahmin & $21(26.9 \%)$ & $24(33.8 \%)$ & & & \\
\hline $21-30$ & $35(44.9 \%)$ & $41(57.7 \%)$ & Chhetri & $15(19.2 \%)$ & $14(19.7 \%)$ & \multirow{3}{*}{ Female } & \multirow{3}{*}{$48(61.5 \%)$} & \multirow{3}{*}{$52(73.2 \%)$} \\
\hline \multirow{2}{*}{$31-40$} & \multirow{2}{*}{$3(3.8 \%)$} & \multirow{2}{*}{$1(1.4 \%)$} & Mongoloid & $6(7.7 \%)$ & $9(12.7 \%)$ & & & \\
\hline & & & Madhesi & $1(1.3 \%)$ & $1(1.4 \%)$ & & & \\
\hline$p$-Value & \multicolumn{2}{|c|}{0.305 (NS) } & \multicolumn{3}{|c|}{0.559 (NS) } & \multicolumn{3}{|c|}{0.089 (NS) } \\
\hline
\end{tabular}

NS: Not significant

Table 2: Dentofacial anomalies with ST bridging (test group) and without bridging (control group)

\begin{tabular}{|l|l|c|c|}
\hline \multicolumn{1}{|c|}{ Anomalies } & Test Group & Control Group \\
\hline \multirow{5}{*}{ Shape } & Dilaceration & 23 & 08 \\
\cline { 2 - 4 } & Malformed root & 02 & 01 \\
\cline { 2 - 4 } & Dens invaginatus & 00 & 01 \\
\cline { 2 - 4 } & Total & $25(17.98 \%)$ & 01 \\
\hline \multirow{5}{*}{ Size } & Microdontia & 08 & $1(1.45 \%)$ \\
\cline { 2 - 4 } & Total & $8(5.75 \%)$ & 01 \\
\hline \multirow{5}{*}{ Position } & Retained deciduous & 03 & 03 \\
\cline { 2 - 4 } & Supernumerary & 04 & 12 \\
\cline { 2 - 4 } & Congenitally missing & 17 & $16(23.18 \%)$ \\
\cline { 2 - 4 } & Total & $24(17.26 \%)$ & 21 \\
\hline \multirow{5}{*}{ Malocclusion } & Impacted teeth & 33 & 03 \\
\cline { 2 - 4 } & Buccally/ palatally erupted & $43(30.93 \%)$ & $24(34.78 \%)$ \\
\cline { 2 - 4 } & Total & 33 & 10 \\
\hline & Rotated tooth & $39(28.05 \%)$ & $18(26.08 \%)$ \\
\cline { 2 - 4 } & Diastema/ spacing & 139 & 62 \\
\cline { 2 - 4 } & Total & Total & 06 \\
\hline
\end{tabular}

Table 3: Association of dental anomalies with test and control groups

\begin{tabular}{|l|c|c|c|c|}
\hline \multirow{2}{*}{$\begin{array}{c}\text { Presence or absence of } \\
\text { anomalies }\end{array}$} & \multicolumn{2}{|c|}{ Test group } & \multirow{2}{*}{$\begin{array}{c}\text { Control group } \\
\text { (No Bridging) }\end{array}$} & \multirow{2}{*}{ p-Value } \\
\cline { 2 - 4 } & Complete bridging & Partial bridging & $35(49.2 \%)$ & \\
\hline Anomalies & $15(46.9)$ & $13(28.3)$ & $16(22.5 \%)$ & \multirow{2}{*}{$0.001^{*}$} \\
\hline More than one anomalies & $15(46.9 \%)$ & $32(69.6 \%)$ & $20(28.2 \%)$ & \\
\hline Absent & $2(6.25 \%)$ & $1(2.2 \%)$ & $71(100 \%)$ & \\
\hline Total & $32(100 \%)$ & $46(100 \%)$ & \\
\hline
\end{tabular}

*Significant at $p<0.05$ 
Table 4: Distribution of ST bridging among different skeletal malocclusions

\begin{tabular}{|l|c|c|c|c|}
\hline \multirow{2}{*}{\multicolumn{1}{c|}{ Extent of bridging }} & \multicolumn{4}{|c|}{ Type of skeletal malocclusion } \\
\cline { 2 - 5 } & Class I & Class II & Class III & Total \\
\hline No bridging & $31(43.66 \%)$ & $25(35.21 \%)$ & $15(21.13 \%)$ & 71 \\
\hline Partial bridging & $4(8.7 \%)$ & $38(82.61 \%)$ & $4(8.7 \%)$ & 46 \\
\hline Complete bridging & $6(18.75 \%)$ & $24(75 \%)$ & $2(6.25 \%)$ & 32 \\
\hline Total & 41 & 87 & 21 & 149 \\
\hline
\end{tabular}

Table 5: Logistic regression analysis of presence of ST bridging and sagittal skeletal relationship

\begin{tabular}{|c|c|c|c|c|c|c|c|}
\hline \multirow{2}{*}{ Relation } & \multirow{2}{*}{ B } & \multirow{2}{*}{ Wald } & \multirow{2}{*}{ df } & \multirow{2}{*}{ Odds ratio } & \multicolumn{2}{|c|}{$95 \% \mathrm{Cl}$} & \multirow{2}{*}{$p$-Value } \\
\hline & & & & & Lower & Upper & \\
\hline Class I & - & 27.512 & 2 & - & - & - & $0.000 *$ \\
\hline Class II & -0.215 & 0.127 & 1 & 0.806 & 0.247 & 2.638 & 0.722 \\
\hline Class III & 1.825 & 11.501 & 1 & 6.200 & 2.160 & 17.797 & $0.001 *$ \\
\hline
\end{tabular}

*Significant at $p<0.05$

\section{DISCUSSION}

Development of craniofacial complex is a complex process with cranial neural crestal cells coordinating a complex series of morphogenetic steps. ${ }^{17}$ These cells migrate dorsolaterally and along with the ectoderm form two important facial primordial processes, namely frontonasal process and first branchial arch; which in turn form the proximal maxilla and mandible. ${ }^{18}$ After migration, they undergo sequential and reciprocal interactions, differentiating into dental epithelial progenitor cells., ${ }^{6,7}$ Derivatives of them frame the shape of anterior wall of the ST and anterior portion of the pituitary gland (adenophysis). Kjaer $^{19}$ concluded that, malformations in the anterior wall of ST are associated with the abnormalities in frontonasal, maxillary and palatine fields. Thus, any alteration in the morphology of ST may be associated with pituitary gland disorders and dentofacial anomalies. , $20^{20}$

Numerous studies have suggested bridging as the most common variant of ST morphology. ${ }^{1,3,4,13,14}$ Bridging can be appreciated at the age of six, although it can also develop later. ${ }^{10,15}$ In the literature, bridging has been mentioned as both normal and pathological variant of ST. ${ }^{14}$ Many studies have determined bridging in relation to dentofacial anomalies, but those studies were limited to anomalies like palatally displaced canine, mandibular second premolar aplasia, dental transposition or a particular

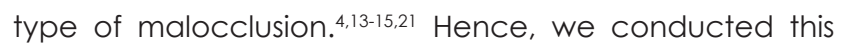
study to evaluate possible dentofacial anomalies given by International Classification of Diseases to Dentistry and Stomatology ${ }^{16}$ seen in the subjects with ST bridging, and to correlate them to subjects having normal STs.
The present study revealed $59.2 \%$ subjects presented with normal ST shape, which is similar to the findings in the available literature.5,12 The presence of bridging (complete/partial) was found in $16.5 \%$ with no correlation to age and gender. These findings are also similar to the previous studies. 2,13,14,22 Our study reported no significant association between ethnicity and the bridging. This study also reported the occurrence of dentofacial anomalies increased with bridging, compared to the subjects with normal ST shape. This finding supports previous studies correlating dentofacial anomalies with ST bridging. ${ }^{1,4,13,14}$ Additionally, skeletal Class ॥ was more common in ST bridging. However, this finding was not supported by previous studies, where skeletal Class III was more common in subjects with bridging. ${ }^{12,23}$ This difference can be explained by the fact that, skeletal Class II is more common than skeletal Class III in Nepalese population. ${ }^{24,25}$

\section{CONCLUSION}

Findings of the present study support crucial relationship between cranial and dentofacial growth and development of the pituitary gland including sella turcica. Consequently, lateral cephalometric radiographs should be observed carefully; any alteration of sella turcica morphology especially bridging can be used as a diagnostic tool to predict as well as initiating preventive and early treatment of dentofacial anomalies. 


\section{REFERENCES}

1. Jones RM, Faqir A, Millet DT, Moos KF, McHugh S. Bridging and dimensions of sella turcica in subjects treated by surgical-orthodontic means or orthodontics only. Angle Orthod 2005; 75:714-8.

2. Axelsson S, Storhaug K, Kjaer I. Post $\neg$ natal size and morphology of the sella turcica. Longitudinal cephalometric standards for Norwegians between 6 and 21 years of age. Eur J Orthod. 2004; 26:597-604.

3. Kucia A, Jankowski T, SiewniakM, Janiszewska-Olszowska J, Grocholewicz K, Szych Z, Wilk G. Sella turcica anomalies on lateral cephalometric radiographs of Polish children. Dentomaxillofac Radiol. 2014; 43:165.

4. Meyer-Marcotty P, Reuther T, Stellzig-Eisenhaver A. Bridging of the sella turcica in skeletal Class III subjects. Eur J Orthod. 2010 ; 32 (2):148-53.

5. Alkofide EA. The shape and size of the sella turcica in skeletal Class I, Class II, and Class III Saudi subjects. Eur J Orthod. 2007; 29:457-63.

6. Miletich I, Sharpe PT. Neural crest contribution to mammalian tooth formation. Birth Defects Research. Part C, Embryo Today: Reviews. $2004 ; 72: 200-12$.

7. Morotomi T. In vitro differentiation of dental epithelial progenitor cells through epithelial-mesenchymal interactions. Archives Oral Biol. 2005; 50:695-705.

8. Mølsted K, Boers M, Kjaer I. The morphology of the sella turcica in velocardiofacial syndrome suggests involvement of a neural crest developmental field. Am J Med Genet Part A. 2010; 152:1450-7.

9. Cederberg RA, Benson BW, Nunn M, English JD. Calcification of the interclinoid and petroclinoid ligaments of sella turcica: A radiographic study of the prevalence. Orthod Craniofacl Res. 2003; 4:227-32.

10. Meyer $\neg$ Marcotty P, Weisschuh N, Dressler P, Hartmann J, Stellzig $\urcorner$ Eisenhaver A. Morphology of thesella turcica in Axenfeld $\neg$ Rieger syndrome with PITX2 mutation. J Oral Pathol Med. 2008; 37:504-10.

11. Koshino T, Konno T, Ohzeki T. Bone and joint manifestations of Rieger's syndrome: A report of a family. J Pediatr Orthop. 1989; 9:224-30.

12. Sathyanarayana HP, Kailasam V, Chitharanjan AB. Sella turcica --lts importance in orthodontics and craniofacial morphology. Dent Res J (Isfahan). 2013; 10(5):571-5.

13. Becktor J P, Einersen S, Kjaer I. A sella turcica bridge in subjects with severe craniofacial deviations. Eur J Orthod. 2000; 22 : 69-74

14. Leonardi R, Barbato E, Vichi M, Caltabiano M. A sella turcica bridge in subjects with dental anomalies. Eur J Orthod. 2006; 28:580-5.

15. Leonardi R, Farella M, Cobourne MT. An association between sella turcica bridging and dental transposition. Eur J Orthod. 2011 ; $33: 461-5$.

16. Application of the International Classification of Diseases to Dentistry \& Stomatology (ICD-DA), 3rd ed. Geneva, World Health Organization, 1994. Available from: http://apps.who.int/iris/bitstream/10665/40919/1/9241544678_eng.pdf.

17. Adameyko I, Fried K. The nervous system orchestrates and integrates craniofacial development: A Review. Front Physiol. $2016 ; 7: 49$.

18. Sharpe PT. Neural crest and tooth morphogenesis. Adv Dent Res. 2001; 15:4-7.

19. Kjaer I. Orthodontics and foetal pathology: A personal view on craniofacial patterning. Eur J Orthod. 2010; 32:140-7.

20. Kjaer I. Sella turcica morphology and the pituitary gland: A new contribution to craniofacial diagnostics based on histology and neuroradiology. Eur J Orthod. 2015; 37(1):28-36.

21. Nielsen BW, Molsted K, Kjaer I. Maxillary and sella turcica morphology in newborns with cleft lip and palate. Cleft Palate Craniofac J. 2005; 42:610-7.

22. Kantor ML, Norton LA. Normal radiographic anatomy and common anomalies seen in cephalometric films. Am J Orthod Dentofac Orthop. 1987; 91:414-26.

23. Abdel ᄀKader HM. Sella turcica bridges in orthodontic and orthognathic surgery patients. A retrospective cephalometric study. Aust Orthod J. 2007; 23:30-5.

24. Shrestha BK, Yadav R, Basel P. Prevalence of malocclusion among high school students in Kathmandu valley. Orthod J Nep. 2012; 2(1):1-5.

25. Shrestha S, Shrestha RM. An analysis of malocclusion and occlusal characteristics in Nepalese orthodontic patients. Orthod J Nep. 2013; $3(1): 19-25$. 